\title{
Immunohistochemical Detection of Imidazolone, a Novel Advanced Glycation End Product, in Kidneys and Aortas of Diabetic Patients
}

\author{
Toshimitsu Niwa, ${ }^{\star}$ Tomoyuki Katsuzaki, ${ }^{\ddagger}$ Shigeru Miyazaki,§ Takashi Miyazaki," Yayoi Ishizaki, ${ }^{\star}$ Fumitaka Hayase, \\ Noriyuki Tatemichi, ${ }^{\ddagger}$ and Yoshifumi Takei ${ }^{\ddagger}$ \\ *Nagoya University, Daiko Medical Center, Nagoya 461, Japan; ${ }^{\ddagger}$ Maruko Pharmaceutical Co., Ltd.; ${ }^{\S}$ Shinrakuen Hospital; and ${ }^{\|}$Meiji University
}

\begin{abstract}
To investigate the role of the Maillard reaction in the pathogenesis of diabetic complications, we produced several clones of monoclonal antibodies against advanced glycation end products (AGEs) by immunizing mice with AGE-modified keyhole limpet hemocyanin, and found that one clone (AG-1) of the anti-AGE antibodies reacted specifically with imidazolones $\mathrm{A}$ and $\mathrm{B}$, novel AGEs. Thus, the imidazolones, which are the reaction products of the guanidino group of arginine with 3-deoxyglucosone (3-DG), a reactive intermediate of the Maillard reaction, were found to be common epitopes of AGE-modified proteins produced in vitro. We determined the erythrocyte levels of imidazolone in diabetic patients using ELISA with the monoclonal anti-imidazolone antibody. The imidazolone levels in the erythrocytes of diabetic patients were found to be significantly increased as compared with those of healthy subjects. Then we studied the localization of imidazolone in the kidneys and aortas obtained from diabetic patients by immunohistochemistry using the antibody. Specific imidazolone immunoreactivity was detected in nodular lesions and expanded mesangial matrix of glomeruli, and renal arteries in an advanced stage of diabetic nephropathy, as well as in atherosclerotic lesions of aortas. This study first demonstrates the localization of imidazolone in the characteristic lesions of diabetic nephropathy and atherosclerosis. These results, taken together with a recent demonstration of increased serum 3-DG levels in diabetes, strongly suggest that imidazolone produced by 3-DG may contribute to the progression of long-term diabetic complications such as nephropathy and atherosclerosis. (J. Clin. Invest. 1997. 99:1272-1280.) Key words: imidazolone - diabetes mellitus - nephropathy - atherosclerosis • Maillard reaction
\end{abstract}

\section{Introduction}

Glucose reacts nonenzymatically with protein amino groups to initiate glycation, the early stage of the Maillard reaction. This process begins with the conversion of reversible Schiff base adducts to stable, covalently bound Amadori rearrangement products. The levels of the Amadori products on numerous

Address correspondence to Toshimitsu Niwa, Nagoya University, Daiko Medical Center, 1-1-20, Daiko-minami, Higashi-ku, Nagoya 461, Japan. Phone: +81-52-723-1111; FAX: +81-52-722-0973.

Received for publication 19 September 1996 and accepted in revised form 8 January 1997.

J. Clin. Invest.

(C) The American Society for Clinical Investigation, Inc. 0021-9738/97/03/1272/09 \$2.00

Volume 99, Number 6, March 1997, 1272-1280 proteins are elevated in proportion to the degree of hyperglycemia in diabetes mellitus. In the intermediate stage of the Maillard reaction, the Amadori products can then undergo multiple dehydration and rearrangements to produce highly reactive carbonyl compounds such as 3-deoxyglucosane (3-deoxyD-erythro-hexos-2-ulose, 3-DG) ${ }^{1}$ (1-4) (Fig. 1), which reacts again with free amino groups, leading to crosslinking and browning of the proteins via the formation of advanced glycation end products (AGEs) in the late stage of the Maillard reaction. Several compounds such as $\mathrm{N}^{\epsilon}$-(carboxymethyl)-L-lysine (CML) (5), pyrraline (6), pentosidine (7), and crosslines (8) have been proposed as candidates for the structure of AGE.

The modification of long-lived proteins with AGEs has been hypothesized to contribute to the development of pathologies associated with diabetes mellitus (9-12), aging (13), dialysis-related amyloidosis (14-18), and Alzheimer disease (19$21)$. The in vivo presence of AGEs has been demonstrated in hemoglobin (12), lens crystalline (13), $\beta 2$-microglobulin $(\beta 2 \mathrm{~m})$ (14-18), $\beta$-amyloid peptide and tau protein (19-21). It has also been shown that AGE peptides accumulate in the circulation of diabetic and nondiabetic patients with uremia $(22,23)$. Immunohistochemistry using antipyrraline antibody (24) and anti-AGE antibody (25) showed that pyrraline and AGE have been reported to be localized in the extracellular matrix of sclerosed glomeruli from diabetic patients with advanced nephropathy.

Incubation of 3-DG with proteins leads to the formation of pyrraline (26) and pentosidine (27), which have been identified in human tissue proteins such as collagen and lens proteins. 3-DG has also been suggested to be a hydrolysis product of fructose-3-phosphate, which was identified in the lens of diabetic rats (28). These data suggest that the formation of 3-DG can occur during the Maillard reaction in vivo and be involved in the development of diabetic complications. Recently, we developed a sensitive and specific gas chromatography/mass spectrometry using a stable isotope dilution method for measuring 3-DG in human serum, and found that serum 3-DG levels were elevated in both diabetic (29) and uremic patients $(17,30)$.

Recently, imidazolone compounds have been isolated from the incubation mixture of $3-\mathrm{DG}$ and an arginine derivative as novel AGEs $(31,32)$. It has been reported that 3-DG first attacks arginine residues in proteins, and then reacts with the lysine residues under physiological conditions at $37^{\circ} \mathrm{C}, \mathrm{pH} 7.4$ $(1,2)$. We produced several clones of monoclonal anti-AGE

1. Abbreviations used in this paper: 3-DG, 3-deoxyglucosone; AGE, advanced glycation end product; $\beta 2 \mathrm{~m}$, $\beta 2$-microglobulin; Benz-Argamide, $N^{\alpha}$-benzoyl-L-arginine amide; CML, $N^{\epsilon}$-(carboxymethyl)L-lysine; imidazolone A, 2-(4-benzoylamino-5-pentamide)-amino5-(2,3,4-trihydroxybutyl)-4(5H)-imidazolone; imidazolone B, 2-(4-benzoylamino-5-pentamide)-amino-5-(2,3,4-trihydroxybutyl)-4-imidazolone; KLH, keyhole limpet hemocyanin; Tos-CML-Me, $N^{\alpha}-p$-tosyl$N^{\epsilon}$-(carboxymethyl)-L-lysine-methyl ester. 


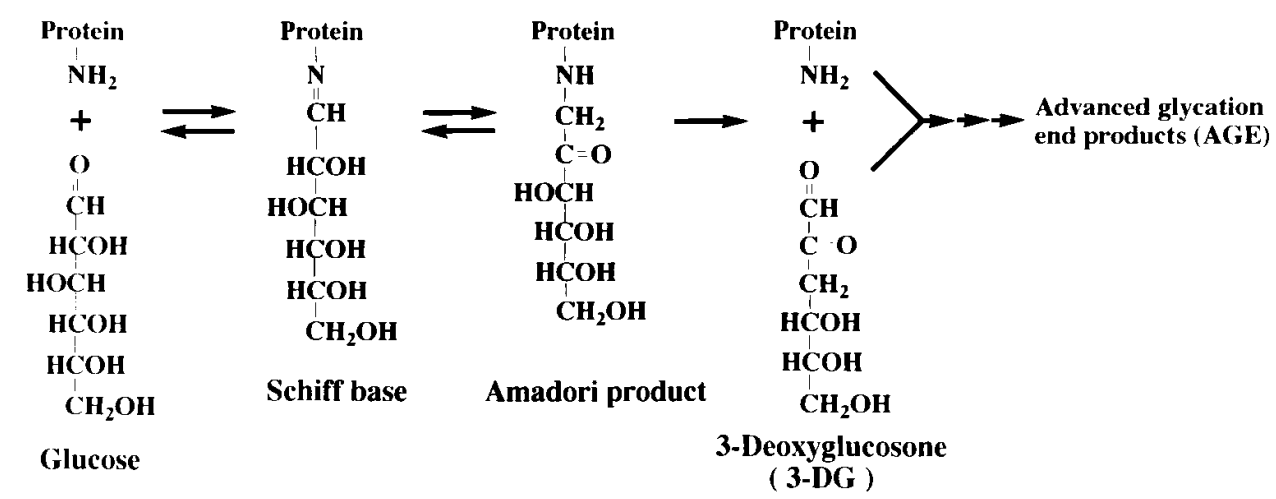

Figure 1. Nonenzymatic synthesis of 3-DG and advanced glycation end products in the Maillard reaction. antibodies and found that one of the antibodies specifically reacted with imidazolones.

In this study, we provide the first immunohistochemical demonstration of imidazolone in renal and aortic tissue sections from diabetic patients using the monoclonal anti-imidazolone antibody we had produced.

\section{Methods}

Patients. Blood samples were obtained using heparinized tubes from 33 diabetic patients and 10 healthy subjects. The blood sample $(5 \mathrm{ml})$ was centrifuged to separate erythrocytes from plasma. After removing plasma, the erythrocyte fraction was stored at $-20^{\circ} \mathrm{C}$ until sample preparation for the assay of imidazolone. The erythrocyte levels of imidazolone were measured using ELISA with the anti-imidazolone antibody (AG-1). The erythrocytes were hemolyzed by melting the frozen samples at room temperature.

Kidney tissues were obtained by autopsy from five diabetic patients with nephropathy and three nondiabetic patients without renal disease, and by biopsy from two diabetic patients with nephropathy and seven nondiabetic patients with renal disease. Aortic tissues were obtained by autopsy from eight diabetic patients (five nonuremic and three uremic) and nine nondiabetic patients (four nonuremic and five uremic).

In vitro preparation of AGE-modified proteins and lysine analog, and known AGE structures. AGE-modified keyhole limpet hemocyanin (AGE-KLH), AGE-modified human serum albumin (AGEHSA), AGE-modified bovine serum albumin (AGE-BSA), and AGE-modified $\beta 2 \mathrm{~m}$ were produced by incubating KLH (20 g/liter), HSA (100 g/liter), BSA (100 g/liter), or $\beta 2 \mathrm{~m}$ (100 mg/liter) (all from Sigma Chemical Co., St. Louis, MO), respectively, at $37^{\circ} \mathrm{C}$ for 1 mo (HSA, BSA, $\beta 2 \mathrm{~m}$ ) or $3 \mathrm{mo}(\mathrm{KLH})$ with $1 \mathrm{M}$ glucose in $0.2 \mathrm{M}$ phosphate buffer, $\mathrm{pH} 7.4$, containing $0.02 \% \mathrm{NaN}_{3}$.

3-DG (1 M) was incubated with $2 \mathrm{M} N^{\alpha}$-p-tosyl-L-lysine-methyl ester (Tos-Lys-Me; Sigma Chemical Co.) in $0.2 \mathrm{M}$ phosphate buffer,

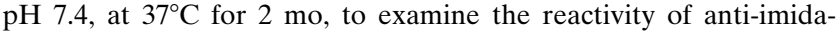
zolone antibody with the incubation solution. Arginine $(0.1 \mathrm{M})$ was incubated with $0.2 \mathrm{M}$ glyoxal, $0.2 \mathrm{M}$ methylglyoxal (all from Sigma Chemical Co.) or $0.2 \mathrm{M} 3$-DG in $0.2 \mathrm{M}$ phosphate buffer, $\mathrm{pH} 7.4$, at $37^{\circ} \mathrm{C}$ for 1 mo to further examine the reactivity of anti-imidazolone antibody with the incubation solution.

$N^{\alpha}-p$-tosyl- $N^{\epsilon}$-(carboxymethyl)-L-lysine-methyl ester (Tos-CML$\mathrm{Me}$ ) was synthesized as reported by us (18). CML derivative of BSA (CML-BSA) was synthesized as reported by Kato et al. (33). Pentosidine was synthesized according to the method of Sell and Monnier (7). Caproyl pyrraline was synthesized according to the method of Hayase et al. (26). Tos-CML-Me, pentosidine, and caproyl pyrraline were confirmed to be pure using nuclear magnetic resonance spectrometry and mass spectrometry.

In vitro preparation of imidazolone compounds. 3-DG $(0.2 \mathrm{M})$ was incubated with $0.1 \mathrm{M} \mathrm{N}{ }^{\alpha}$-benzoyl-L-arginine amide (Benz-Arg-amide;
Nakarai Chemical Co., Kyoto, Japan) in $0.1 \mathrm{M}$ sodium phosphate

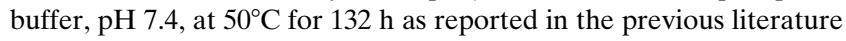
$(31,32)$. As shown in Fig. 2, two imidazolone compounds, 2-(4-benzoylamino-5-pentamide)-amino-5-(2,3,4,-trihydroxybutyl)-4(5H)-imidazolone (imidazolone A) and 2-(4-benzoylamino-5-pentamide)-amino5-(2,3,4-trihydroxybutyl)-4-imidazolone (imidazolone B) were purified from the incubation solution by high performance liquid chromatography.

Production of monoclonal anti-imidazolone antibody. Monoclonal anti-AGE antibodies were produced by immunizing mice with AGE$\mathrm{KLH}$ as described in detail in the previous paper (16). The antibodies in the culture medium were cloned by sandwich ELISA using antimouse IgG antibody-coated plate, AGE-HSA, and peroxidase-labeled anti-HSA antibody, and then two monoclonal clone types of antiAGE antibodies (AG-1 and AG-10) were raised. Recently, the epitope of AG-10 has been found to be CML (18).
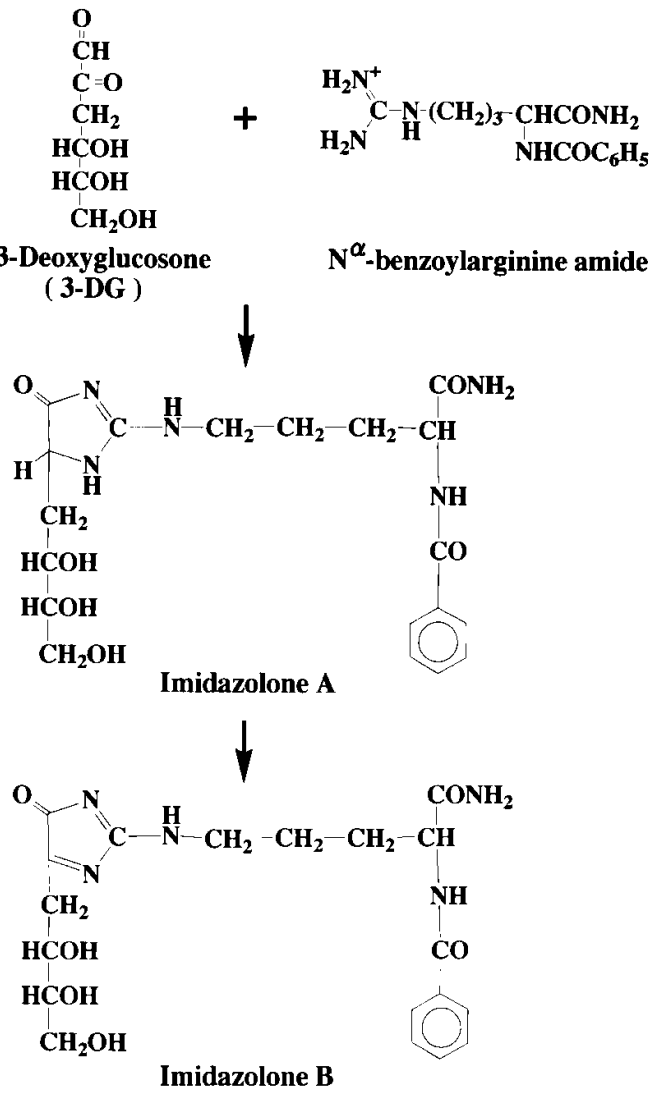

Figure 2. Production of imidazolone compounds $(A$ and $B)$ by in vitro incubation of 3-DG and an arginine derivative, Benz-Argamide. 


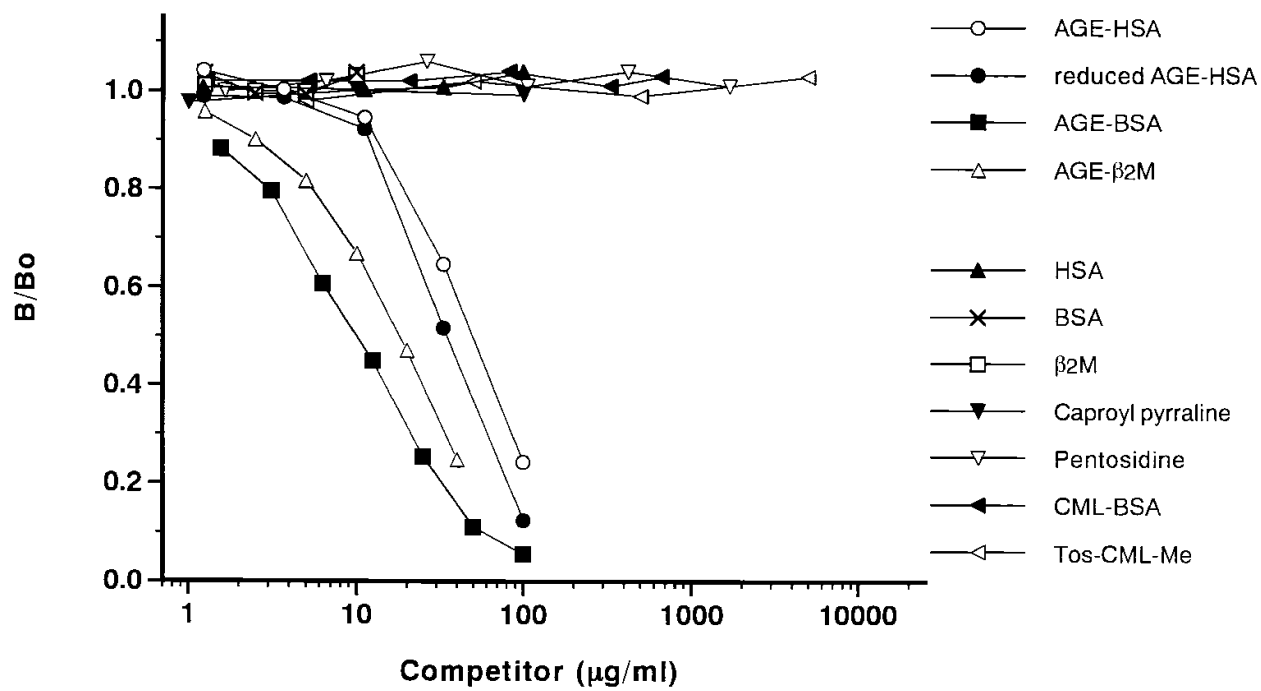

Figure 3. Competitive ELISA demonstrating the specificity of monoclonal anti-imidazolone antibody (AG-1). The anti-imidazolone antibody reacted with AGE-HSA, reduced AGE-HSA, AGE-BSA, and AGE- $\beta_{2} \mathrm{~m}$, but did not react with HSA, BSA, or $\beta_{2} \mathrm{~m}$. Thus, the antibody recognizes a common epitope of AGE-proteins. However, the anti-AGE antibody did not react at all with well-known AGE structures like CML (Tos-CML-Me, CMLBSA), pyrraline, or pentosidine.
Sample preparation for ELISA of imidazolone in erythrocytes. Hemolyzed solution $(100 \mu \mathrm{l})$ was mixed with distilled water $(300 \mu \mathrm{l})$ and toluene $(300 \mu \mathrm{l})$. After centrifugation at $1,500 \mathrm{~g}$ for $30 \mathrm{~min}$, the supernatant lipid layer was removed. The water layer was reduced with $50 \mathrm{mM} \mathrm{NaBH}_{4}$ solution at $37^{\circ} \mathrm{C}$ for $1 \mathrm{~h}$. After cooling with ice for $7 \mathrm{~min}$, TCA $(1.2 \mathrm{ml})$ was added to the reduced solution and kept cool with ice for $30 \mathrm{~min}$. After centrifugation at $1,500 \mathrm{~g}$ for $45 \mathrm{~min}$, the supernatant was removed and the precipitated protein was dissolved by adding $0.1 \mathrm{M} \mathrm{NaOH}(0.45 \mathrm{ml})$ at $4^{\circ} \mathrm{C}$ for $2 \mathrm{~d}$. After neutralizing the solution with $0.5 \mathrm{M}$ boric acid, the neutral solution was diluted two or four times with PBS, and then the diluted solution $(25 \mu \mathrm{l})$ was assayed for imidazolone using competitive ELISA. The protein concentration of the solution was measured by the Lowry method. Then the imidazolone content was expressed as arbitrary units per milligram protein.

Competitive sandwich ELISA of imidazolone. Sample solution $(25 \mu \mathrm{l})$ or standard AGE-HSA $(0-200 \mathrm{mg} / \mathrm{liter})$ was incubated at room temperature for $1 \mathrm{~h}$ in AGE-HSA ( $0.01 \mathrm{~g} /$ liter)-coated microplate with PBS containing $0.25 \%$ BSA $(50 \mu \mathrm{l})$ and peroxidase conjugated anti-AGE antibody (AG-1). After washing four times with PBS, $o$-phenylenediamine $(100 \mu \mathrm{l})$ was added to the microplate. Reaction was stopped by adding $1.6 \mathrm{M} \mathrm{H}_{2} \mathrm{SO}_{4}(100 \mu 1)$, and absorption at $492 \mathrm{~nm}$ was measured using $620 \mathrm{~nm}$ as control.

Immunohistochemical detection of imidazolone in renal tissues and aortas. Immunostaining of imidazolone in renal tissue sections was conducted using the streptavidin-biotinylated peroxidase complex method with the biotin-labeled monoclonal anti-imidazolone antibody (AG-1). The biotin-labeled monoclonal antibody was produced using a protein biotinylation module (Amersham International, Little Chalfont, UK). The antibody (1 mg) in bicarbonate buffer ( $\mathrm{pH}$ 8.6) was reacted with $N$-hydroxysuccinimide-biotin by mixing at room temperature for $1 \mathrm{~h}$, and consequently the mixture was applied on a Sephadex G-25 column in PBS containing 1\% BSA. The biotin-labeled antibody was collected by eluting with $5 \mathrm{ml}$ PBS and monitoring ultraviolet absorbance at $280 \mathrm{~nm}$.

The tissue specimens were divided into thin sections (1- $\mu \mathrm{m}$ thick) that were then deparaffinized. The sections were washed with PBS for $20 \mathrm{~min}$. The sections were treated with $0.01-1 \%$ pronase (Merck, Darmstadt, Germany) in distilled water at $37^{\circ} \mathrm{C}$ for $30 \mathrm{~min}$, and washed thrice with PBS. Then the sections were incubated with the biotin-labeled monoclonal anti-imidazolone antibody (AG-1) $(5 \mu \mathrm{g} /$ $\mathrm{ml}$ ) dissolved in PBS containing 3\% BSA at $4{ }^{\circ} \mathrm{C}$ overnight, and washed thrice with PBS. Endogenous peroxidase activity was blocked by incubating the sections with $0.3 \% \mathrm{H}_{2} \mathrm{O}_{2}$ in methanol for $20 \mathrm{~min}$ at room temperature. The sections were washed thrice with PBS, and then incubated with peroxidase-labeled streptavidin (Nichirei, Tokyo, Japan) at $37^{\circ} \mathrm{C}$ for $30 \mathrm{~min}$. After washing thrice with PBS, the re- action was completed by the addition of diaminobenzidine- $\mathrm{H}_{2} \mathrm{O}_{2}$ solution for $15 \mathrm{~min}$. After washing with PBS, the slides were counterstained with methylgreen.

Imidazolone in aortic tissues was studied using the peroxidaseantiperoxidase method with monoclonal anti-imidazolone antibody as reported by us (16). The tissue specimens were divided into thin sections that were then deparaffinized. The sections were washed with PBS for $20 \mathrm{~min}$. Endogenous peroxidase activity was blocked by incubating the sections with $0.3 \% \mathrm{H}_{2} \mathrm{O}_{2}$ in methanol for 5 to $30 \mathrm{~min}$. The sections were washed with PBS and incubated with $5 \%$ normal rabbit serum in PBS at $37^{\circ} \mathrm{C}$ for $20 \mathrm{~min}$. After removing the normal rabbit sera, the sections were incubated with either monoclonal antiimidazolone antibody (AG-1), or monoclonal anti-CD68 antibody (DAKOPATTS, Copenhagen, Denmark) at $4^{\circ} \mathrm{C}$ overnight. The sections were washed with PBS and incubated with the second antibody, rabbit polyclonal anti-mouse immunoglobulin antibody (Zymed Laboratories, Inc., San Francisco, CA), at $37^{\circ} \mathrm{C}$ for $60 \mathrm{~min}$. After washing thrice with PBS, the sections were incubated with mouse polyclonal peroxidase-anti-peroxidase complex (Nordic Immunological Laboratories, Netherlands) at $37^{\circ} \mathrm{C}$ for 30 to $60 \mathrm{~min}$. After washing thrice with PBS, the reaction was completed by the addition of diaminobenzidine $-\mathrm{H}_{2} \mathrm{O}_{2}$ solution for 5 to $30 \mathrm{~min}$. After washing with PBS, the slides were counterstained with hematoxylin.

In these experiments, the slides were read by a pathologist in a blinded fashion and scored on a semiquantitative scale (zero to +++ ) according to the degree of positive staining.

\section{Results}

Characterization of monoclonal anti-imidazolone antibody. The reactivity of the anti-AGE antibody (AG-1) with reduced AGE-HSA, AGE-BSA, or AGE- $\beta 2 \mathrm{~m}$ was studied using the competitive ELISA. Fig. 3 shows the reactivity of the monoclonal anti-AGE antibody (AG-1) with the AGE-modified proteins, demonstrating that the anti-AGE antibody recognizes a common epitope of AGE-modified proteins. That the anti-AGE antibody was unreactive with early Amadori glycation products was confirmed by the observation that sodium borohydride reduction, which alters the Amadori product epitope, did not affect the reactivity of the antibody to AGEHSA once formed. However, the anti-AGE antibody did not react at all with Tos-CML-Me, CML-BSA, caproyl pyrraline, or pentosidine. The anti-AGE antibody also did not react with the incubation solution of lysine and glucose, the major product of which was CML. Thus, the anti-AGE antibody was 


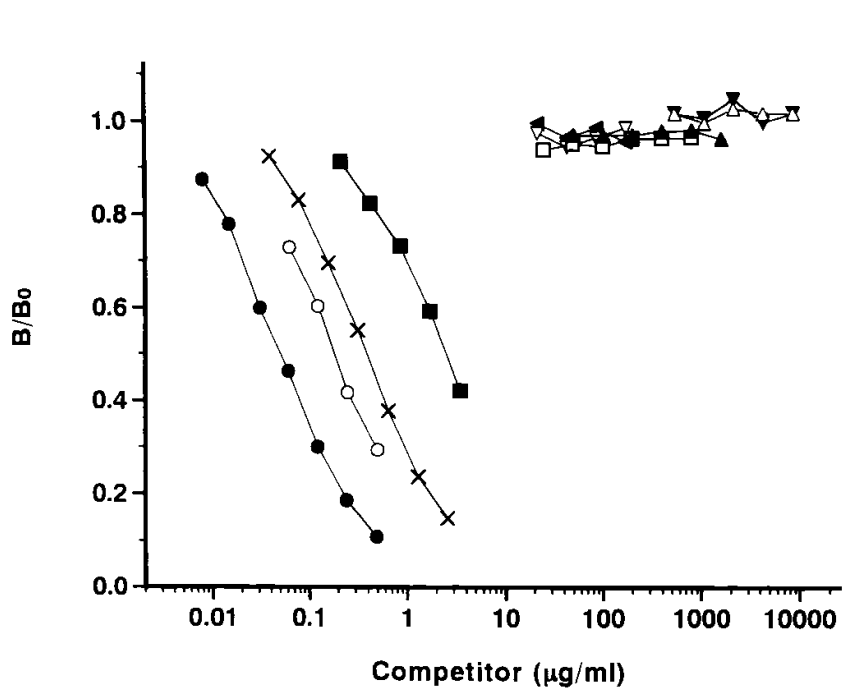

demonstrated to not react with Amadori products, nor wellknown AGE structures like CML, pyrraline, or pentosidine.

The epitope of the anti-AGE antibody (AG-1) was found to be imidazolone, since the antibody reacted with imidazolone A, imidazolone $\mathrm{B}$, and the incubation solution of 3-DG and Benz-Arg-amide, but did not react with 3-DG or BenzArg-amide (Fig. 4). The antibody did not react with the incubation solution of 3-DG and Tos Lys-Me, the major product of which was CML. The antibody reacted with the incubation solutions of 3-DG and arginine, but did not react with the incubation solutions of the other 1,2-dicarbonyl compounds (glyoxal or methylglyoxal) and arginine. These results demonstrate that the epitope of the antibody is the imidazolone ring coupling with at least a partial structure of 3-DG, and that the direct precursor of imidazolone is 3-DG, but not the other dicarbonyl compounds (glyoxal or methylglyoxal).

Levels of imidazolone in erythrocytes of diabetic patients. Table I shows the erythrocyte levels of imidazolone measured by an ELISA using the monoclonal anti-imidazolone antibody (AG-1). The erythrocyte levels of imidazolone were significantly elevated in the diabetic patients as compared with the healthy subjects. The erythrocyte levels of imidazolone in the diabetic patients did not show any significant correlation with $\mathrm{HbA}_{1 \mathrm{c}},(r=0.22)$ or serum fructosamine $(r=0.25)$.

Immunohistochemical detection of imidazolone in renal tissues from diabetic patients with nephropathy. Fig. 5 demonstrates the presence of imidazolone in the glomeruli (Fig. 5, $A-D$ ) and renal artery (Fig. $5 E$ ) from diabetic patients ( 78 and 59 yr old, male) with advanced nephropathy. Immunostaining with antiimidazolone antibody demonstrated that imidazolone was noted especially in the nodular lesions (Fig. 5, $A-D$ ) of the glomeruli, and in the renal arterial wall (Fig. $5 E$ ) from the diabetic patients. Imidazolone was also noted in a crescent-shaped structure surrounding the ischemic glomerulus as well as in the nodular lesion (Fig. 5 D). A normal glomerulus from a nondiabetic patient without renal disease ( $71 \mathrm{yr}$ old male) did not show any significant deposition of imidazolone as shown in Fig. $5 F$.

Table II summarizes the immunohistochemical detection

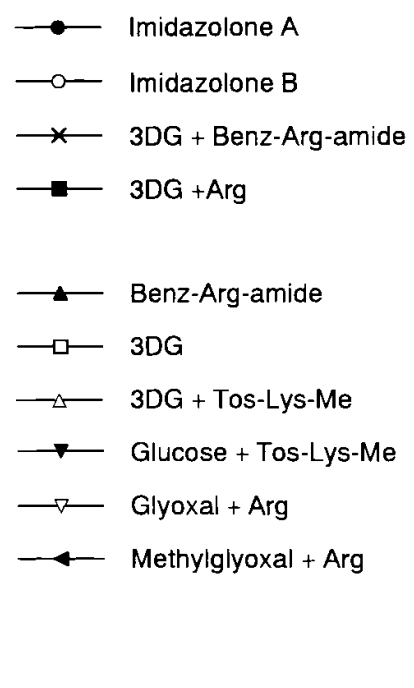

Figure 4. Competitive ELISA demonstrating the specificity of monoclonal anti-imidazolone antibody (AG-1). The anti-imidazolone antibody reacted with imidazolone $\mathrm{A}$, imidazolone B, the incubation solution of 3-DG with Benz-Arg-amide, and the incubation solution of 3-DG with arginine. However, the antibody did not react with 3-DG, BenzArg-amide, the incubation solution of 3-DG with Tos-Lys-Me, the incubation solution of glucose with TosLys-Me, the incubation solution of glyoxal with arginine, or the incubation solution of methylglyoxal with arginine. These results demonstrate that the epitope of the antibody is the imidazolone ring coupling with at least a partial structure of 3-DG, and that the direct precursor of imidazolone is 3-DG, but not the other dicarbonyl compounds (glyoxal or methylglyoxal). of imidazolone in the renal tissues from diabetic patients with nephropathy, nondiabetic patients with the other glomerular diseases, and nondiabetic patients without renal diseases. The diabetic patients with nephropathy showed the localization of imidazolone in the nodular lesions, if present, and widened mesangial areas of the glomeruli and renal arterial walls, but did not show any significant deposition of imidazolone in the fibrinoid caps. On the other hand, the nondiabetic patients did not show any deposition of imidazolone in the glomeruli. However, all the patients regardless of the presence of diabetes showed the deposition of imidazolone in the renal tubular cells, although it was more prominent in the diabetic patients as compared with nondiabetic patients.

Immunohistochemical detection of imidazolone in aortic tissues from diabetic patients. Fig. $6 \mathrm{~A}$ demonstrates the presence of imidazolone in aortic tissues from a diabetic patient $(85 \mathrm{yr}$ old male) with atherosclerosis by immunostaining with antiimidazolone antibody. Imidazolone was noted in the intima and media of the aortic tissues. Fig. 6, $B$ and $C$ demonstrates the cellular localization of imidazolone in CD-68-positive macrophages. Table III summarizes the immunohistochemical detection of imidazolone in the aortic tissues from diabetic and age-matched nondiabetic patients with or without uremia. Atherosclerotic lesions were composed of diffuse intimal thickening, fatty streaks, and/or atherosclerotic plaques. All the atherosclerotic aortas from diabetic and nondiabetic patients showed the localization of imidazolone in the aortic walls.

Table I. Imidazolone Contents in the Erythrocytes of Diabetic Patients and Healthy Subjects

\begin{tabular}{lcc}
\hline & $\begin{array}{c}\text { Healthy subjects } \\
n=10\end{array}$ & $\begin{array}{c}\text { Diabetic patients } \\
n=33\end{array}$ \\
\hline $\begin{array}{l}\text { Erythrocyte imidazolone } \\
\quad \text { (arbitrary U/mg protein) }\end{array}$ & $4.8 \pm 0.2$ & $8.7 \pm 0.2^{*}$ \\
$\mathrm{HbA}_{1 \mathrm{c}}(\%)$ & $5.0 \pm 0.1$ & $8.2 \pm 0.3^{*}$ \\
Serum fructosamine $(\mu \mathrm{M})$ & $285 \pm 5$ & $381 \pm 12^{*}$ \\
& & \\
\hline
\end{tabular}

$* P<0.01$ as compared with healthy subjects by Student's $t$ test. 

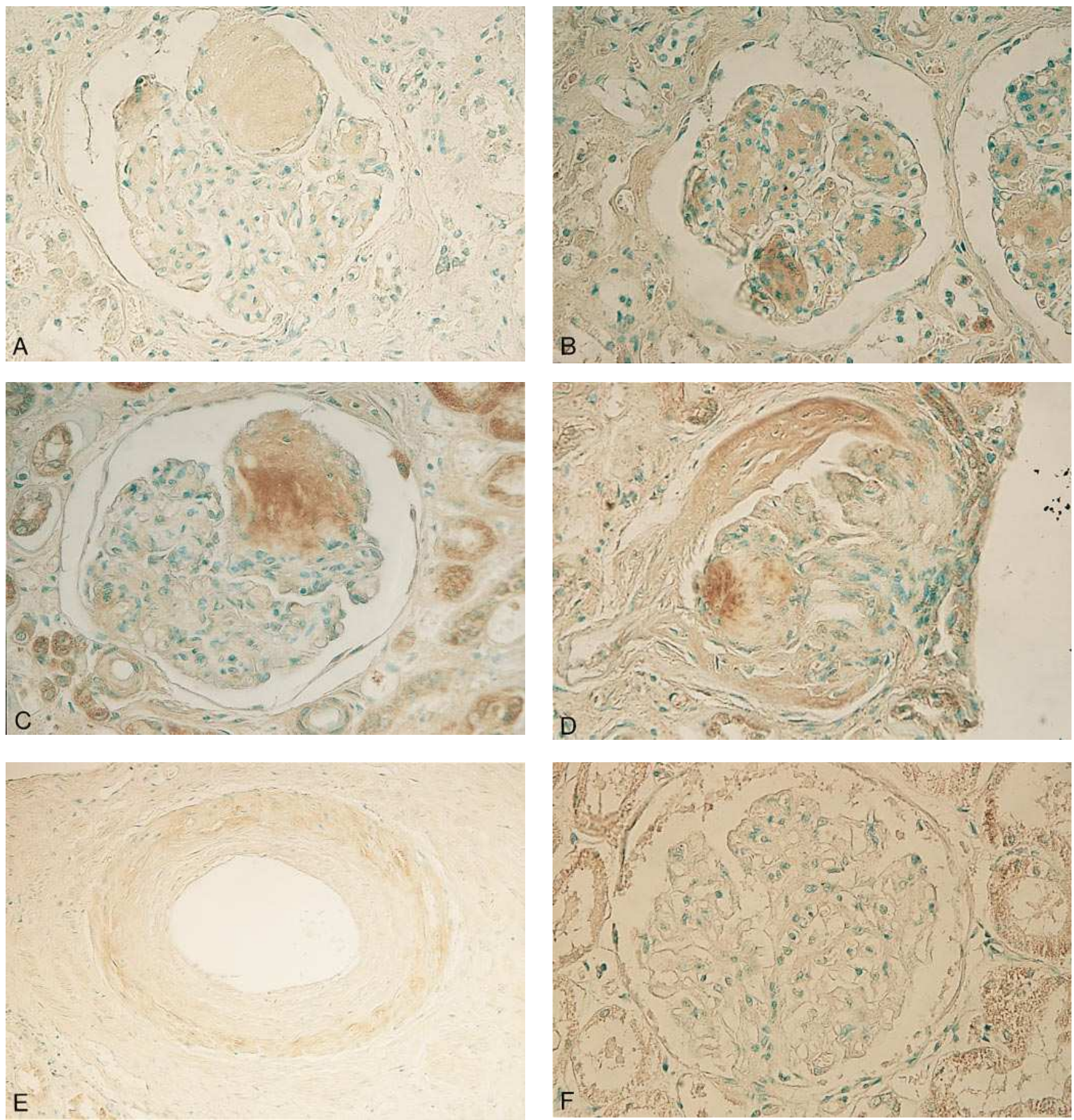

Figure 5. Light micrographs of glomeruli $(A$ and $B)(400 \times)$ and artery $(E)(200 \times)$ from a diabetic patient (78 yr old male) with advanced nephropathy, glomeruli $(C$ and $D)(400 \times)$ from another diabetic patient (59 yr old male) with advanced nephropathy, and a normal glomerulus $(F)$ $(400 \times)$ from a nondiabetic patient (71 yr old male) without renal disease obtained by immunostaining using anti-imidazolone antibody (AG-1). Imidazolone was noted especially in the nodular lesions $(A-D)$ of the glomeruli, and in the renal artery wall $(E)$ from the diabetic patients with advanced nephropathy. The normal glomerulus $(F)$ from a nondiabetic patient did not show any significant localization of imidazolone.

\section{Discussion}

Our results demonstrate that imidazalone, a novel AGE, is present in erythrocytes, renal tissues, and aortic walls from diabetic patients. More notably, imidazolone was localized in the characteristic nodular lesions of diabetic glomerulosclerosis. Since imidazolone was also localized in the atherosclerotic lesions of the aorta from not only diabetic patients but also non- diabetic patients, imidazolone accumulation in the aorta may be associated with the progression of atherosclerosis. CML has been reported to be a dominant AGE antigen in tissue proteins (5), but we consider that imidazolone is another dominant AGE antigen in tissue proteins.

Formation of an imidazolone ring was reported in the incubation solution of an arginine residue and methylglyoxal (34). 
Table II. Immunohistochemical Detection of Imidazolone in Renal Tissues of Patients With Diabetic Nephropathy and the Other Diseases

\begin{tabular}{|c|c|c|c|c|c|c|c|c|c|c|}
\hline \multirow[b]{2}{*}{ Patient } & \multirow[b]{2}{*}{ Age } & \multirow[b]{2}{*}{ Sex } & \multirow[b]{2}{*}{$\begin{array}{l}\text { Duration of } \\
\text { diabetes (yr) }\end{array}$} & \multirow[b]{2}{*}{$\mathrm{S}-\mathrm{Cr}(\mathrm{mg} / \mathrm{dl})$} & \multicolumn{6}{|c|}{ Immunostaining of renal tissue using anti-imidazolone antibody } \\
\hline & & & & & Mesangium & $\begin{array}{c}\text { Nodular } \\
\text { lesion }\end{array}$ & $\begin{array}{l}\text { Sclerosed } \\
\text { glomeruli }\end{array}$ & Interstitium & $\begin{array}{l}\text { Tubular } \\
\text { cell }\end{array}$ & $\begin{array}{l}\text { Arterial } \\
\text { wall }\end{array}$ \\
\hline \multicolumn{11}{|l|}{ Disease } \\
\hline Diabetic nephropathy & 78 & M & 22 & 1.4 & +++ & +++ & ND & - & + & +++ \\
\hline Diabetic nephropathy & 59 & M & 10 & 1.6 & + & +++ & ++ & + & +++ & + \\
\hline Diabetic nephropathy & 53 & M & 21 & 3.8 & + & + & + & - & + & - \\
\hline Diabetic nephropathy & 64 & $\mathrm{~F}$ & 24 & 5.4 & + & ND & + & + & ++ & + \\
\hline Diabetic nephropathy & 79 & $\mathrm{~F}$ & 26 & 5.3 & + & ND & + & - & ++ & + \\
\hline Diabetic nephropathy & 62 & M & 10 & 4.7 & + & ND & ++ & - & +++ & ++ \\
\hline Diabetic nephropathy & 58 & M & 18 & 0.9 & + & ND & + & - & + & + \\
\hline Minimal change NS & 16 & $\mathrm{~F}$ & & 0.9 & - & ND & ND & - & + & - \\
\hline FSGS & 65 & M & & 1.3 & - & ND & ND & - & + & ND \\
\hline IgA nephropathy & 46 & $\mathrm{M}$ & & 1.2 & - & ND & ND & - & + & - \\
\hline IgA nephropathy & 28 & $\mathrm{M}$ & & 1.0 & - & ND & ND & - & + & ND \\
\hline MPGN type 1 & 69 & $\mathrm{~F}$ & & 2.7 & - & ND & ND & - & + & + \\
\hline Lupus nephritis type 3 & 39 & $\mathrm{~F}$ & & 1.2 & - & ND & ND & - & ++ & - \\
\hline End-stage kidney & 23 & M & & 3.3 & - & ND & - & - & + & - \\
\hline Normal kidney & & & & & & ND & & & & \\
\hline Parkinson disease & 71 & $\mathrm{M}$ & & 1.0 & - & ND & ND & - & + & - \\
\hline Stomach cancer & 69 & M & & 1.1 & - & ND & ND & - & + & - \\
\hline Cancer & 64 & M & & 1.1 & - & ND & ND & - & + & - \\
\hline
\end{tabular}

M, male; F, female; ND, not detected; NS, nephrotic syndrome; FSGS, focal segmental glomerulosclerosis; MPGN, membranoproliferative glomerulonephritis.

However, our antibody does not react with the incubation solution of arginine and methylglyoxal (or glyoxal), demonstrating that our antibody does not recognize the imidazolone ring alone. Since our antibody reacts with the incubation solution of an arginine residue and 3-DG, the antibody recognizes the imidazolone ring coupling with at least partial structure of 3-DG. In other words, our antibody is specific for 3-DG-derived imi- dazolone and not for methylglyoxal (or glyoxal)-derived imidazolone. Thus, the imidazolone detected using our antibody was formed by 3-DG but not by methylglyoxal or glyoxal.

Imidazolone contents in the erythrocytes of diabetic patients were significantly elevated as compared with healthy subjects. We found that the erythrocyte levels of $3-\mathrm{DG}$, the precursor of imidazolone, were markedly high as compared

Table III. Immunohistochemical Detection of Imidazolone in Aortic Walls from Diabetic and Nondiabetic Patients

\begin{tabular}{|c|c|c|c|c|c|c|}
\hline Patient & Cause of death & Age & Sex & Duration on hemodialysis (yr) & Atherosclerosis & Imidazolone \\
\hline \multirow[t]{5}{*}{ Diabetes, nonuremic } & Acute myocardial infarction & 85 & M & & + & + \\
\hline & Hepatic failure & 71 & M & & + & + \\
\hline & Amyotrophic lateral sclerosis & 71 & $\mathrm{~F}$ & & + & + \\
\hline & Hepatoma & 68 & M & & + & + \\
\hline & Amyotrophic lateral sclerosis & 64 & M & & - & - \\
\hline \multirow[t]{3}{*}{ Diabetes, uremic } & Congestive cardiac failure & 54 & M & 4 & ++ & + \\
\hline & Sudden death & 50 & M & 2 & + & + \\
\hline & Sepsis & 52 & M & 0.1 & + & + \\
\hline \multirow[t]{4}{*}{ Nondiabetes, nonuremic } & Sepsis & 74 & M & & - & \pm \\
\hline & Pneumonia & 74 & $\mathrm{~F}$ & & + & + \\
\hline & Duodenum cancer & 71 & $\mathrm{~F}$ & & + & + \\
\hline & Duodenum cancer & 67 & $\mathrm{M}$ & & + & + \\
\hline \multirow[t]{5}{*}{ Nondiabetes, uremic } & Gastrointestinal bleeding & 76 & $\mathrm{~F}$ & 11 & + & ++ \\
\hline & Hemorrhagic shock & 69 & $\mathrm{~F}$ & 20 & - & \pm \\
\hline & Hypercalcemia & 68 & $\mathrm{M}$ & 24 & + & + \\
\hline & Acute myocardial infarction & 70 & $\mathrm{M}$ & 4 & ++ & + \\
\hline & Colon cancer & 66 & $\mathrm{~F}$ & 20 & + & + \\
\hline
\end{tabular}

M, male; F, female. 

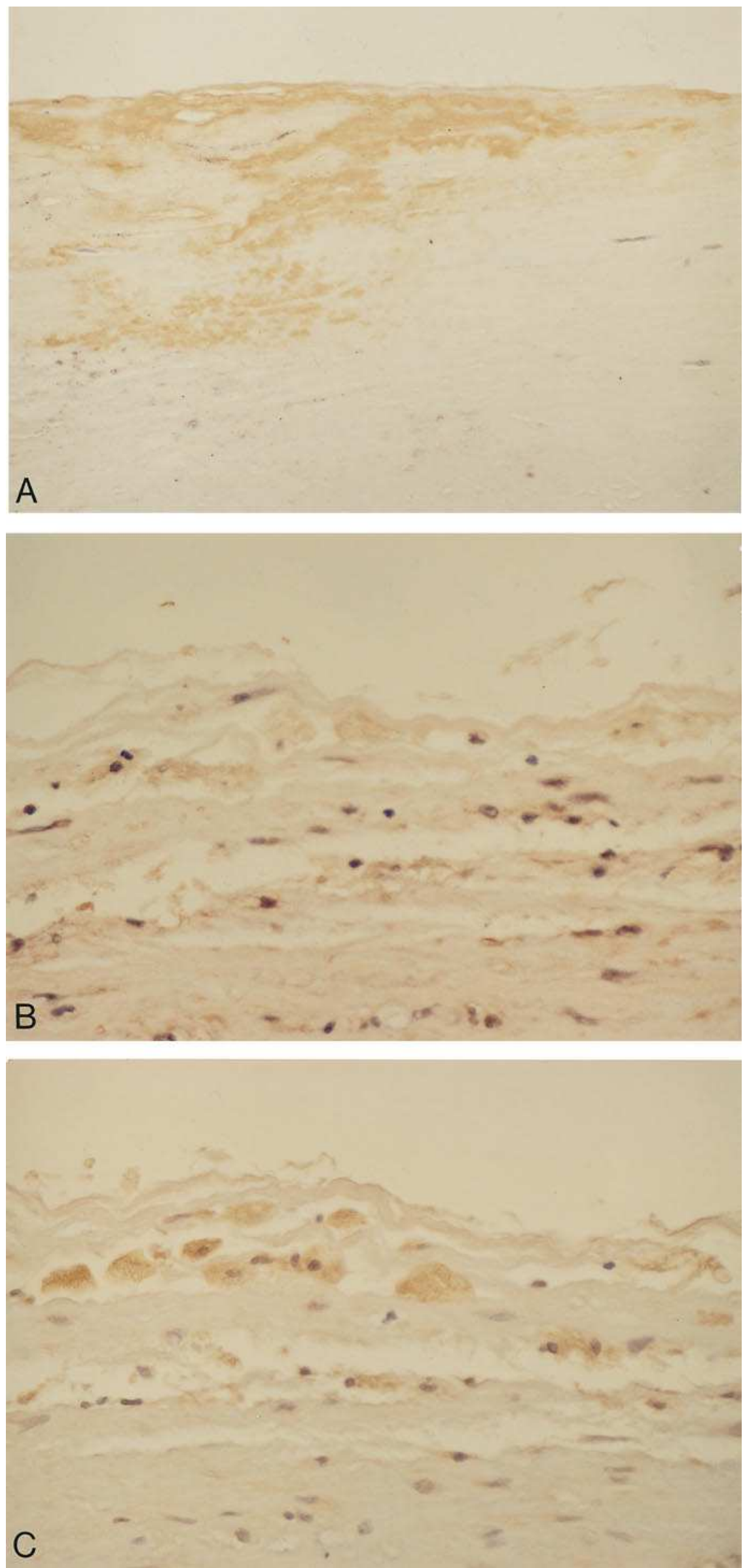

Niwa et al.
Figure 6. Light micrographs of aortic wall from a diabetic patient ( $85 \mathrm{yr}$ old male) $(A)(50 \times)$ with atherosclerosis by immunostaining with anti-imidazolone antibody and of serial sections of aortic wall by immunostaining with anti-imidazolone antibody $(B)(100 \times)$ and anti-CD-68 antibody $(C)(100 \times)$. Imidazolone was noted in the intima and media of the aortic tissues from the diabetic patients. Imidazolonepositive cells were $\mathrm{CD}$-68-positive macrophages. 
with its serum levels in both healthy subjects and diabetic patients, and that the erythrocyte 3-DG levels in diabetic patients were significantly higher than those in healthy subjects. Thus, the high levels of imidazolone in the diabetic erythrocytes may be due to the high levels of 3-DG in the diabetic erythrocytes. Hemoglobin, a major protein in erythrocytes, may be the dominant protein modified with imidazolone. Thus, imidazolonemodified hemoglobin may be used instead of AGE-hemoglobin for monitoring in vivo AGE formation in diabetic patients, because imidazolone is a chemically identified AGE, but the chemical structure of the epitope of the anti-AGE antibody used for ELISA of AGE hemoglobin (12) has not yet been identified.

AGEs have been reported to be associated with diabetic nephropathy. Miyata and Monnier (24) demonstrated using immunohistochemistry with antipyrraline antibody that pyrraline immunoreactivity was detected in sclerosed glomeruli from diabetic patients and in renal arteries with arteriosclerosis. Since pyrraline is formed by reacting 3-DG with lysine, elevated serum 3-DG levels in diabetes may lead to the increased modification of the extracellular matrix proteins with pyrraline in diabetic glomerulosclerosis. Using immunohistochemistry with an anti-AGE antibody, Makino et al. (25) demonstrated the immunostaining of AGEs in mesangium and, most notably, in nodular lesions of advanced diabetic nephropathy. Their findings are consistent with our results. However, the chemical structure of the epitope that their anti-AGE antibody recognizes has not yet been reported. Our study first demonstrates the localization of imidazolone, a chemicallyidentified novel AGE, in the characteristic nodular lesions of diabetic glomerulosclerosis. Since the direct precursor of imidazolone is $3-\mathrm{DG}$ but not the other dicarbonyl compounds (glyoxal or methylglyoxal), the elevated serum levels of 3-DG in diabetes (29) may result in the increased modification of glomerular extracellular matrix proteins with imidazolone. Imidazolone modification of proteins occurs preferentially in nodular lesions composed of types V and VI collagens, since they are sites of slow turnover. The positive immunostaining of tubular cells in almost all the patients regardless of the presence of diabetes may indicate the reabsorbed imidazolone by the tubular cells, although its intensity was more prominent in diabetes.

Administration of aminoguanidine, an inhibitor of AGE formation, retarded the progression of diabetic nephropathy in rat models (35). Aminoguanidine inhibits AGE formation by reacting with Amadori-derived fragmentation products such as 3-DG, preventing subsequent rearrangement from occurring (36). Administration of AGE-modified albumin daily to healthy rats led to glomerulosclerosis, and the glomerular lesions were ameliorated by coadministration of aminoguanidine (37). Taken together with these reports, the increased modification of glomerular extracellular matrix with AGEs such as imidazolone may contribute to the development of diabetic glomerulosclerosis.

Imidazolone was detected in the aortic tissues of not only diabetic but also nondiabetic patients, including uremia. These findings are consistent with the earlier reports that AGEs were associated with atherosclerotic lesions of aorta regardless of the presence of diabetes as demonstrated by immunohistochemistry using polyclonal (38) or monoclonal anti-AGE antibody (39), although the epitopes of these antibodies have not yet been reported. We consider that imidazolone localization is associated with atherosclerotic lesions because imidazolone was scarcely detected in nonatherosclerotic aortic tissues. Plasma levels of 3-DG are increased in not only diabetic (29) but also uremic patients $(17,30)$, accelerating imidazolone modification of tissue and plasma proteins in diabetes and uremia. In fact, we observed atherosclerosis with imidazolone deposition in aortas of younger (50-54 yr old) patients with both diabetes and uremia as compared with those without diabetes or uremia. Long term exposure of tissue proteins with 3-DG even at its normal plasma levels in nondiabetic and nonuremic aged patients also leads to increased tissue levels of imidazolone, accounting for imidazolone deposition in their aortic tissues with atherosclerosis.

Both extracellular and intracellular AGE accumulation in the intimal lesions of aortic atherosclerosis were observed in relation to aging and the progression of atherosclerosis. Intracellular AGE accumulation was detected in macrophages, macrophage-derived foam cells, and smooth muscle cells (39). We also observed intracellular accumulation of imidazolone in the aortic walls. The imidazolone-positive cells are macrophage or macrophage-derived foam cells because they were positively stained by immunohistochemistry with a monoclonal anti-CD68 antibody. It is not yet known if imidazolone is uptaken by macrophages or foam cells via scavenger receptor, receptor for AGE (RAGE), or the other specific receptor for imidazolone.

AGEs promote endothelial expression of adhesion molecules (VCAM-1, ICAM-1) and consequently atheroma formation (40, 41). Further, within the aortic wall, AGE-modified proteins covalently trap LDL (42) and inactivate nitric oxide activity $(43,44)$, and induce transendothelial monocyte chemotaxis and release platelet-derived growth factor (45). Plasma levels of AGE-modified LDL are increased in diabetic or uremic patients compared with normal subjects (46). The AGE modification of LDL also initiates its oxidative modification, a process that increases the atherogenicity of LDL by promoting its uptake by macrophage scavenger receptor (47). Thus, AGEs are considered to play a major role in the pathogenesis of atherosclerosis. Although the effects of imidazolone on these atherogenic activities are not yet known, imidazolone is a chemically-defined novel AGE and its deposition can be used as an index of colocalization of atherogenic AGEs in the aortic tissues.

We found that the serum levels of 3-DG were markedly increased in not only diabetic patients (29), but also nondiabetic dialysis patients $(17,30)$. 3-DG first attacks arginine residues in proteins, producing imidazolone modification of proteins. Although reactions of proteins with 3-DG are known to produce pyrraline (26), pentosidine (27), and CML $(17,18)$, as well as imidazolone $(31,32)$, imidazolone is a reaction product most specific for 3-DG among these AGE structures. Thus, immunochemical and immunohistochemical detection of imidazolone may be a good marker for 3-DG-derived AGE modification of proteins in aging, diabetes, and uremia.

\section{Acknowledgments}

We thank Prof. Toshihiko Osawa and Dr. Yoji Kato for providing us with CML-BSA and pentosidine. 


\section{References}

1. Kato, H., D.B. Shin, and F Hayase. 1987. 3-Deoxyglucosone crosslinks proteins under physiological conditions. Agric. Biol. Chem. 51:2009-2011.

2. Shin, D.B., F. Hayase, and H. Kato. 1988. Polymerization of proteins caused by reaction with sugars and the formation of 3-deoxyglucosone under physiological conditions. Agric. Biol. Chem. 52:1451-1458.

3. Kato, H. 1962. Chemical studies on amino-carbonyl reaction. Part I. Isolation of 3-deoxypentosone and 3-deoxyhexosones formed by browning degradation of N-glycosides. Agric. Biol. Chem. 26:187-192.

4. Kato, H., R.K. Cho, A. Oitani, and F. Hayase. 1987. Responsibility of 3-deoxyglucosone for the glucose-induced polymerization of proteins. Agric. Biol. Chem. 51:683-689.

5. Reddy, S., J. Bichler, K.J. Wells-Knecht, S.R. Thorpe, and J.W. Baynes. 1995. $\mathrm{N}^{\epsilon}$-(carboxymethyl)lysine is a dominant advanced glycation end product (AGE) antigen in tissue proteins. Biochemistry. 34:10872-10878.

6. Njoroge, F.G., L.M. Sayre, and V.M. Monnier. 1987. Detection of glucose-derived pyrrole compounds during Maillard reaction under physiological conditions. Carbohydr. Res. 167:211-220.

7. Sell, D.R., and V.M. Monnier. 1989. Structure elucidation of a senescence cross-link from human extracellular matrix. J. Biol. Chem. 264:21597-21602.

8. Nakamura, K., T. Hasegawa, Y. Fukunaga, and K. Ienaga. 1992. Crosslines A and B as candidates for the fluorophores in age- and diabetesrelated cross-linked proteins, and their diacetates produced by Maillard reaction of $\alpha-\mathrm{N}$-acetyl-L-lysine with D-glucose J. Chem. Soc. Chem. Commun. 14: 992-994.

9. Brownlee, M., N. Vlassara, and A. Cerami. 1984. Nonenzymatic glycation and the pathogenesis of diabetic complications. Ann. Intern. Med. 101:527-537.

10. Kennedy, L., and J.W. Baynes. 1984. Nonenzymatic glycosylation and chronic complications of diabetes: an overview. Diabetologia. 27:92-98.

11. Monnier, V.M., R.R. Kohn, and A. Cerami. 1984. Accelerated age-related browning of human collagen in diabetes mellitus. Proc. Natl. Acad. Sci. USA. 81:583-587.

12. Makita, Z., H. Vlassara, E. Rayfield, K. Cartwright, E. Friedman, R. Rodby, A. Cerami, and R. Bucala. 1992. Hemoglobin-AGE: a circulating marker of advanced glycosylation. Science (Wash. DC). 58:651-653.

13. Araki, N., N. Ueno, B. Chakrabarti, Y. Morino, and S. Horiuchi. 1992. Immunochemical evidence for the presence of advanced glycation end products in human lens proteins and its positive correlation with aging. J. Biol. Chem. 267:931-939.

14. Miyata, T., O. Oda, R. Inagi, Y. Iida, N. Araki, N. Yamada, S. Horiuchi, N. Taniguchi, K. Maeda, and T. Kinoshita. 1993. $\beta_{2}$-Microglobulin modified with advanced glycation end products is a major component of hemodialysisassociated amyloidosis. J. Clin. Invest. 92:1243-1252.

15. Miyata, T., R. Inagi, Y. Iida, M. Sato, N. Yamada, O. Oda, K. Maeda, and H. Seo. 1994. Involvement of $\beta_{2}$-microglobulin modified with advanced glycation end products in the pathogenesis of hemodialysis-associated amyloidosis. J. Clin. Invest. 93:521-528.

16. Niwa, T., T. Miyazaki, T. Katsuzaki, N. Talemichi, Y. Takei, T. Miyazaki, T. Morita, and Y. Hirasawa. 1995. Immunohistochemical detection of advanced glycation end products in dialysis-related amyloidosis. Kidney Int. 48: $771-778$

17. Niwa, T., T. Katsuzaki, T. Momoi, T. Miyazaki, H. Ogawa, A. Saito, S. Miyazaki, K. Maeda, N. Tatemichi, and Y. Takei. 1996. Modification of $\beta_{2}$-microglobulin with advanced glycation end products as observed in dialysis-related amyloidosis by 3-deoxyglucosone accumulating in uremic serum. Kidney Int. 49:861-867.

18. Niwa, T., M. Sato, T. Katsuzaki, T. Tomoo, T. Miyazaki, N. Tatemichi, Y. Takei, and T. Kondo. 1996. Amyloid $\beta_{2}$-microglobulin is modified with $\mathrm{N}^{\epsilon}$-(carboxymethyl)lysine in dialysis-related amyloidosis. Kidney Int. 50:13031309.

19. Vitek, M.P., K. Bhattacharya, J.M. Glendening, E. Stopa, H. Vlassara, R. Bucala, K. Manogue, and A. Cerami. 1994. Advanced glycation end products contribute to amyloidosis in Alzheimer disease. Proc. Natl. Acad. Sci. USA. 91:4766-4770.

20. Smith, M.A., S. Taneda, P.L. Richey, S. Miyata, S.D. Yan, D. Stern, L.M. Sayer, V.M. Monnier, and G. Perry. 1994. Advanced Maillard reaction end products are associated with Alzheimer disease. Proc. Natl. Acad. Sci. USA. 91:5710-5714.

21. Yan, S.D., X. Chen, A.M. Schmidt, J. Brett, G. Godman, Y.S. Zou, C.W. Scott, C. Caputo, T. Frappier, M.A. Smith, G. Perry, S.H. Yen, and D. Stern. 1994. Glycated tau protein in Alzheimer disease: a mechanism for induction of oxidant stress. Proc. Natl. Acad. Sci. USA. 91:7787-7791.

22. Makita, Z., S. Radoff, E.J. Rayfield, Z.Yang, E. Skolnik, V. Delaney, E.A. Friedman, A. Cerami, and H. Vlassara. 1991. Advanced glycation end products in patients with nephropathy. N. Engl. J. Med. 325:836-842

23. Makita, Z., R. Bucala, E.J. Rayfield, E.A. Friedman, A.M. Kaufman, S.M. Korbet, R.H. Barth, J.A. Winston, H. Fuh, K.R. Manogue, A. Cerami, and H. Vlassara. 1994. Reactive glycosylation endproducts in diabetic uraemia and treatment of renal failure. Lancet. 343:1519-1522.
24. Miyata, S., and V. Monnier. 1992. Immunohistochemical detection of advanced glycation end products in diabetic tissues using monoclonal antibody to pyrraline. J. Clin. Invest. 89:1102-1112.

25. Makino, H., K. Shikata, K. Hironaka, M. Kushiro, Y. Yamasaki, H. Sugimoto, Z. Ota, N. Araki, and S. Horiuchi. 1995. Ultrastructure of nonenzymatically glycated mesangial matrix in diabetic nephropathy. Kidney Int. 48:517-526.

26. Hayase, F., R.H. Nagaraj, S. Miyata, F.G. Njoroge, and V.M. Monnier. 1989. Aging of proteins: immunological detection of a glucose-derived pyrrole formed during Maillard reaction in vivo. J. Biol. Chem. 263:3758-3764.

27. Dyer, D.G., J.A. Blackledge, S.R. Thorpe, and J.W. Baynes. 1991. Formation of pentosidine during nonenzymatic browning of proteins by glucose. $J$. Biol. Chem. 266:11654-11660.

28. Szwergold, B.S., F. Kappler, and T.R. Brown. 1990. Identification of fructose 3-phosphate in the lens of diabetic rats. Science (Wash. DC). 247:451-454.

29. Niwa, T., N. Takeda, H. Yoshizumi, A. Tatematsu, M. Ohara, S Tomiyama, and K. Niimura. 1993. Presence of 3-deoxyglucosone, a potent protein crosslinking intermediate of Maillard reaction, in diabetic serum. Biochem. Biophys. Res. Commun. 196:837-843.

30. Niwa, T., N. Takeda, T. Miyazaki, H. Yoshizumi, A. Tatematsu, K. Maeda, M. Ohara, S. Tomiyama, and K. Niimura. 1995. Elevated serum levels of 3-deoxyglucosone, a potent protein-cross-linking intermediate of the Maillard reaction, in uremic serum. Nephron. 69:438-443.

31. Konishi, Y., F. Hayase, and H. Kato. 1994. Novel imidazolones compound formed by the advanced Maillard reaction of 3-deoxyglucosone and arginine residues in proteins. Biosci. Biotechnol. Biochem. 58:1953-1955.

32. Hayase, F., Y. Konishi, and H. Kato. 1995. Identification of the modified structure of arginine residues in proteins with 3-deoxyglucosone, a Maillard reaction intermediate. Biosci. Biotechnol. Biochem. 59:1407-1411.

33. Kato, Y., K. Tokunaga, and T. Osawa. 1996. Immunochemical detection of carboxymethylated Apo B-100 in copper-oxidized LDL. Biochem. Biophys. Res. Commun. 226:923-927.

34. Lo, T.W.C., M.E. Westwood, A.C. McLellan, T. Selwood, and P.J. Thornalley. 1994. Binding and modification of proteins by methylglyoxal under physiological conditions. J. Biol. Chem. 269:32299-32305.

35. Soulis-Liparota, T., M. Cooper, D. Papazoglou, B. Clarke, and G. Jerums. 1991. Retardation by aminoguanidine of development of albuminuria, mesangial expansion, and tissue fluorescence in streptozotocin-induced diabetic rats. Diabetes. 40:1328-1334

36. Edelstein, D., and M. Brownlee. 1992. Mechanistic studies of advanced glycosylation end product inhibition by aminoguanidine. Diabetes. 41:26-28.

37. Vlassara, H., L.J. Striker, S. Teichberg, H. Fuh, Y.M. Li, and M. Steffes. 1994. Advanced glycation end products induce glomerular sclerosis and albuminuria in normal rats. Proc. Natl. Acad. Sci. USA. 91:11704-11708.

38. Nakamura, Y., Y. Horii, T. Nishino, H. Shiiki, Y. Sakaguchi, T. Kagoshima, K. Dohi, Z. Makita, H. Vlassara, and R. Bucala. 1993. Immunohistochemical localization of advanced glycosylation end products in coronary atheroma and cardiac tissue in diabetes mellitus. Am. J. Pathol. 143:1649-1656.

39. Kume, S., M. Takeya, T. Mori, N. Araki, H. Suzuki, S. Horiuchi, T. Kodama, Y. Miyauchi, and K. Takahashi. 1995. Immunohistochemical and ultrastructural detection of advanced glycation end products in atherosclerotic lesions of human aorta with a novel specific monoclonal antibody. Am. J. Pathol. 147:654-667.

40. Vlassara, H., H. Fuh, T. Donnelly, and M. Cybulsky. 1995. Advanced glycation endproducts promote adhesion molecule (VCAM-1, ICAM-1) expression and atheroma formation in normal rabbits. Mol. Med. 1:447-456.

41. Schmidt, A.M., O. Hori, J.X. Chen, J.F. Li, J. Crandall, J. Zhang, R. Cao, S.D. Yan, J. Brett, and D. Stern. 1995. Advanced glycation endproducts interacting with their endothelial receptor induce expression of vascular cell adhesion molecule-1 (VCAM-1) in cultured human endothelial cells and in mice. A potential mechanism for the accelerated vasculopathy of diabetes. J. Clin. Invest. 96:1395-1403.

42. Brownlee, M., H. Vlassara, and A. Cerami. 1985. Nonenzymatic glycosylation products on collagen covalently trap low density lipoprotein. Diabetes. 34:938-941.

43. Bucala, R., K.J. Tracey, and A. Cerami. 1991. Advanced glycosylation products quench nitric oxide and mediate defective endothelium-dependent vasodilatation in experimental diabetes. J. Clin. Invest. 87:432-438.

44. Hogan, M., A. Cerami, and R. Bucala. 1992. Advanced glycosylation endproducts block the antiproliferative effect of nitric oxide. Role in the vascular and renal complications of diabetes mellitus. J. Clin. Invest. 90:1110-1115.

45. Kirstein, M., J. Brett, S. Radoff, S. Ogawa, D. Stern, and H. Vlassara 1990. Advanced protein glycosylation induces transendothelial human monocyte chemotaxis and secretion of platelet-derived growth factor: role in vascular disease of diabetes and aging. Proc. Natl. Acad. Sci. USA. 87:9010-9014.

46. Bucala, R., Z. Makita, G. Vega, S. Grundy, T. Koschinsky, A. Cerami, and H. Vlassara. 1994. Modification of low density lipoprotein by advanced glycation end products contributes to the dyslipidemia of diabetes and renal insufficiency. Proc. Natl. Acad. Sci. USA. 91:9441-9445.

47. Steinberg, D., S. Parthasarathy, T.E. Carew, J.C. Khoo, and J.L. Witztum. 1989. Beyond cholesterol. Modifications of low density lipoprotein that increases its atherogenicity. N. Engl. J. Med. 320:915-924. 